\title{
Gossypol Interferes with Both Type I and Type II Topoisomerase Activities Without Generating Strand Breaks
}

\author{
Muge Senarisoy $\cdot$ Pakize Canturk · Sevil Zencir • \\ Yusuf Baran · Zeki Topcu
}

Published online: 16 November 2012

(c) Springer Science+Business Media New York 2012

\begin{abstract}
A considerable number of agents with chemotherapeutic potentials reported over the past years were shown to interfere with the reactions of DNA topoisomerases, the essential enzymes that regulate conformational changes in DNA topology. Gossypol, a naturally occurring bioactive phytochemical is a chemopreventive agent against various types of cancer cell growth with a reported activity on mammalian topoisomerase II. The compounds targeting topoisomerases vary in their mode of action; class I compounds act by stabilizing covalent topoisomeraseDNA complexes resulting in DNA strand breaks while class II compounds interfere with the catalytic function of topoisomerases without generating strand breaks. In this study, we report Gossypol as the interfering agent with type I topoisomerases as well. We also carried out an extensive set of assays to analyze the type of interference manifested by Gossypol on DNA topoisomerases. Our results strongly suggest that Gossypol is a potential class II inhibitor as it blocked DNA topoisomerase reactions with no consequently formed strand breaks.
\end{abstract}

M. Senarisoy · P. Canturk

Department of Biotechnology, Graduate School of Natural and Applied Sciences, Ege University, Izmir, Turkey

\section{S. Zencir}

Department of Medical Biology, Faculty of Medicine, Pamukkale University, Denizli, Turkey

Y. Baran

Department of Molecular Biology and Genetics, Izmir Institute of Technology, Izmir, Turkey

Z. Topcu $(\square)$

Department of Pharmaceutical Biotechnology, Faculty

of Pharmacy, Ege University, Izmir 35100, Turkey

e-mail: zeki.topcu@ege.edu.tr
Keywords DNA topoisomerases - Gossypol · Anticancer drug research $\cdot$ DNA strand breaks

\section{Introduction}

Gossypol [GSP; 2,2'-bis(8-Formyl-1,6,7-trihydroxy-5-isopropyl-3-methylnaphthalene)] is a natural polyphenol derived from cotton plant (Gossypium, Malvaceae) [1-3]. It is a promising compound with a number of chemotherapeutic potentials [4]. Gossypol was reported to inactivate intracellular dehydrogenases, protein kinases, and type II DNA topoisomerases [5-7]. Among these enzymes, DNA topoisomerases gained a considerable attention over the past years as they are the cellular targets of many clinically important agents [8-10]. These enzymes are found in prokaryotes, eukaryotes, viral systems, and cellular organelles such as mitochondria and chloroplasts with important roles in replication, transcription, recombination, and repair [10]. Topoisomerases regulate the DNA topology with concerted breakage and reunion of DNA strands [8]. Two types of topoisomerases based on their reaction mechanisms are known; type I topoisomerases introduce single-stranded breaks while type II topoisomerases introduce double-stranded breaks in the DNA molecules during their catalytic cycles [11].

Since the identification of Camptothecine (CPT) from Camptotheca acuminata as topoisomerase-targeting compound, several compounds with therapeutical potential were analyzed through topoisomerase reactions [12-19]. However, biological activity assays employing DNA topoisomerases in vast majority of these studies are limited to supercoil relaxations, a well-known approach to monitor either type I or type II activities in the presence of a test compound. Given the information obtained with such assays, 
the results are not conclusive enough to predict the type of interaction of the test compound with enzyme-DNA complexes. This is an important issue because topoisomerasetargeting anticancer drugs are divided into two classes that vary widely in their mechanisms of actions. The class I drugs include acridines, anthracyclines, actinomycins, ellipticines, alkaloids, epipodophyllotoxins, isoflavodins, and quinolones, collectively called as "topoisomerase poisons" because they act by stabilizing covalent topoisomeraseDNA complexes. Class II-drugs, by contrast, interfere with the catalytic function of the enzyme without stabilizing the covalent DNA-enzyme complex. The drugs in this class are referred to as "topoisomerase inhibitors." The main topoisomerase inhibitors are coumarin antibiotics and fostriecin analogs [9]. Based on the biological activity reports on GSP, our laboratory carried out an extended set of analyses using topoisomerases in the absence or the presence of varying concentrations of this compound. We aimed to identify if the effect of GSP would cover other topoisomerases as well as clarifying the type of the detected interference of GSP on these enzymes by employing supercoil relaxations, decatenations, strand cleavage, and covalent-complex analyses. Our results strongly suggested that GSP has a potential to be considered as class II compound, interfering with the catalytic functions of both type I and type II topoisomerases without generating strand breaks.

\section{Materials and Methods}

\section{Plasmid Supercoil Relaxation Assays}

Plasmid supercoil relaxation assays were done out as described [20]. Briefly, $20 \mu \mathrm{L}$ of reaction mixture contained $500 \mathrm{ng}$ of superhelical circular (sc) plasmid DNA and one unit (u) of either calf thymus type I or mammalian type II topoisomerase (Inspiralis, Norwich, UK) in reaction buffers [35 mM Tris- $\mathrm{HCl}(\mathrm{pH}$ 8.0), $72 \mathrm{mM} \mathrm{KCl,} 5 \mathrm{mM}$ $\mathrm{MgCl}_{2}, 5 \mathrm{mM}$ dithiothreitol (DTT), $5 \mathrm{mM}$ spermidine, and $0.1 \%$ bovine serum albumin for type I topoisomerase and $50 \mathrm{mM}$ Tris-Cl (pH 8.0), $120 \mathrm{mM} \mathrm{KCl}, 10 \mathrm{mM} \mathrm{MgCl}$. $0.5 \mathrm{mM}$ ATP, $0.5 \mathrm{mM}$ DTT for type II topoisomerase] in the presence or the absence of the varying concentrations of GSP (Sigma-Aldrich, St. Louis, MO, USA), dissolved in $100 \%$ dimethylsulfoxide (DMSO). Reactions were terminated with stop buffer (5\% sarkosyl, $0.0025 \%$ bromophenol blue, $25 \%$ glycerol) and relaxation products were seperated on $1 \%$ agarose gel in TAE buffer [ $40 \mathrm{mM}$ Tris-acetate and $1 \mathrm{mM}$ EDTA (pH 8.0)] in a horizontal electrophoresis apparatus $(5 \mathrm{~V} / \mathrm{cm})$ (Thermo, Massachusetts, USA) and photographed under UV light after staining in ethidium bromide (Etd-Br) solution $(0.5 \mu \mathrm{g} / \mathrm{mL})$. DNA bands were quantified from gel photo images using
BioRad Multianalyst (ver. 1.1) (Vilber Lourmat, Paris, France). The relationship between the binding of Etd-Br and the amount of fluorescence given by sc and relaxed DNA (rlx DNA) under UV light was carried out as described [21]. One unit of enzyme activity (Inspiralis, Norwich, UK) was taken as the activity removing the supercoils from $500 \mathrm{ng}$ of sc plasmid substrate pBR322 at $37{ }^{\circ} \mathrm{C}$ in $30 \mathrm{~min}$. The $\mathrm{IC}_{50}$ values, the concentration of the test compound that reveals $50 \%$ interference on the topoisomerase reactions were calculated as described [22].

\section{DNA Minicircle Decatenation Assays}

Decatenation assays were carried out using $200 \mathrm{ng}$ kinetoplast DNA (kDNA) substrate and one unit of either topoisomerase II or topoisomerase IV (Topogen, Florida, USA) in a final volume of $20 \mu \mathrm{L}$ in reaction buffer, composed of $50 \mathrm{mM}$ Tris- $\mathrm{Cl}$ ( $\mathrm{pH}$ 8.0), $120 \mathrm{mM} \mathrm{KCl}, 10 \mathrm{mM} \mathrm{MgCl}$. $0.5 \mathrm{mM}$ ATP, $0.5 \mathrm{mM}$ DTT. Reactions were terminated with stop buffer $(5 \%$ sarkosyl, $0.0025 \%$ bromophenol blue, $25 \%$ glycerol) and electrophoretic analyses of kDNA were performed using $1 \%$ agarose gel containing Etd- $\mathrm{Br}(0.5 \mu \mathrm{g} / \mathrm{mL})$. Resolution of decatenated DNA products were monitored as stated above. One unit of type II activity was defined as the amount of enzyme decatenating $200 \mathrm{ng}$ of $\mathrm{kDNA}$ in $15 \mathrm{~min}$ at $37^{\circ} \mathrm{C}$. Average band intensities were calculated from three independent reactions in both type I and type II topoisomerase assays. Camptothecin and Etoposide were used as positive controls for topoisomerase I and topoisomerase II assays, respectively.

\section{DNA Strand Break and Covalent Complex Analyses}

DNA strand breaks were analyzed in $30 \mu \mathrm{L}$ reaction volumes containing $500 \mathrm{ng}$ substrat DNA (pBR322 or pRYG) using 4-20 units of enzyme.The reactions were carried out at $37{ }^{\circ} \mathrm{C}$ for $15 \mathrm{~min}$ and terminated by the addition of $1 \%$ sodium dodecyl sulfate (SDS) and $0.5 \mu \mathrm{g} / \mathrm{mL}$ Proteinase K (Prot-K). Following the extraction of samples with phenol:chloroform:isoamylalcohol (PCI) $(25: 24: 1 \mathrm{v} / \mathrm{v})$, formation of linear DNA was monitored using $1 \%$ agarose gel in the presence of $0.5 \mu \mathrm{g} / \mathrm{mL}$ Etd-Br. Covalent complex analyses were carried out as described above except that the reactions were analyzed both in the presence and the absence of Prot-K. All the figures submitted as the results of activity assays with topoisomerases in the presence of GSP were representative for the reactions, each experiment was repeated twice.

\section{Results and Discussion}

We carried out biochemical assays for plasmid DNA nicking and DNA decatenation to monitor type I and type 
II topoisomerases, respectively, in the presence or the absence of GSP. The former assay relies on the ability of topoisomerases to relax sc DNA substrates. Interference by GSP was monitored according to the migration pattern of substrate and product DNA molecules on agarose gel. A representative supercoil relaxation assay using decreasing concentrations of GSP is given in Fig. 1. Supercoil plasmid substrate, pBR322 (Fig. 1, lane 1) was relaxed by topo I (Fig. 1, lane 2) in the absence of GSP while this activity was not significantly influenced by $10 \%$ DMSO, used in dissolving GSP (Fig. 1, lane 3). The relaxation of supercoils was profoundly affected in the presence of 0.1 volume of 1 and $0.5 \mathrm{mM}$ GSP (Fig. 1, lanes 4 and 5, respectively). The faster migrating sc band was decreased when GSP was diluted to 0.2 and $0.1 \mathrm{mM}$ (Fig. 1, lanes 6 and 7, respectively). The interference disappeared in the presence of $0.05 \mathrm{mM}$ of GSP (Fig. 1, lane 8). Densitometric calculations of relative band intensities showed that the interference was as high as 100-95\% at 0.1 volume of 1 and $0.5 \mathrm{mM}$ GSP concentrations, respectively, and this value gradually decreased to 70-65 \% upon serial dilutions while approaching to $0 \%$ at 0.1 volume of $0.05 \mathrm{mM} \mathrm{GSP}$, which gave rise to an $\mathrm{IC}_{50}$ value of $15 \mu \mathrm{M}$ (Fig. 1). The interference obtained by GSP was in a comparable degree to that of CPT (data not shown). Residual nicked-circular DNA present in plasmid was taken into account during quantitative evaluations.

We next employed decatenation assays in the presence or the absence of GSP using a type II enzyme, topo IV. Decatenation is a type II topoisomerase-specific assay employing kDNA, the mitochondrial DNA of Crithidia fasciculata as a catenated network of DNA rings, the majority of which are $2.5 \mathrm{~kb}$ monomers [23]. The assay takes advantage of inclusion of Etd-Br thereby seperating open-circular (OC) monomers from covalently closed circular (CCC) DNA population. As seen in Fig. 2, the kDNA was too large to enter the gel (Fig. 2, lane 1), while the enzyme yielded monomeric DNA rings (Fig. 2, lane 2). A remarkable degree of interference was obtained on topoisomerase IV-catalyzed decatenation in the presence of 0.1 volume of 1 and $0.1 \mathrm{mM}$ GSP (Fig. 2, lanes 3 and 4, respectively) while diluting GSP to $0.2 \mathrm{mM}$ diminished the interference (Fig. 2, lane 5) as the banding pattern of the latter lane approached to decatenation activity of enzyme (Fig. 2, lane 2) obtained in the absence of GSP. Quantitative evaluation of the interference revealed an average of 90,78 , and $27 \%$ change in decatenation when $1,0.1$, and $0.2 \mathrm{mM}$ GSP in respective order were included in reaction mixture with an estimated $\mathrm{IC}_{50}$ value of $15 \mu \mathrm{M}$ (Fig. 2). We obtained a comparable effect of GSP on topoisomerase II-catalyzed decatenation assays as well (data not shown).

Both assays given above are frequently employed in topoisomerase-based biological activity studies; however, the results from such assays do not lead to identify the pathway test compound follows in exerting its function. We next investigated GSP to identify whether its inclusion in the reaction mixture resulted in the formation of DNA strand breaks or it was the enzyme's catalytic properties changed by GSP. We set the topoisomerase II reactions as defined above using pRYG plasmid, a 54 bp DNA substrate of high affinity to topo II with repeating purine and pyrimidine bases, and then employed $1 \%$ SDS to terminate enzyme's catalysis. Following the Prot-K digestion and PCI extraction, we monitored DNA strand breaks by the formation of linearized DNA. Because of the nature of strand break analyses, we used a higher amount of enzyme (4-20 units per reaction) in these assays and employed Etoposide, a known topo II-targeting agent as a positive control. Fig. 3 shows a representative agarose gel run in the presence of Etd-Br. Supercoiled pRYG substrate (Fig. 3a, lane 2) was relaxed with topoisomerase II (Fig. 3a, lane 3) without a significant effect by DMSO (Fig. 3a, lane 4). The control compound yielded a remarkable amount of DNA strand breaks (Fig. 3a, lane 5) that showed the same
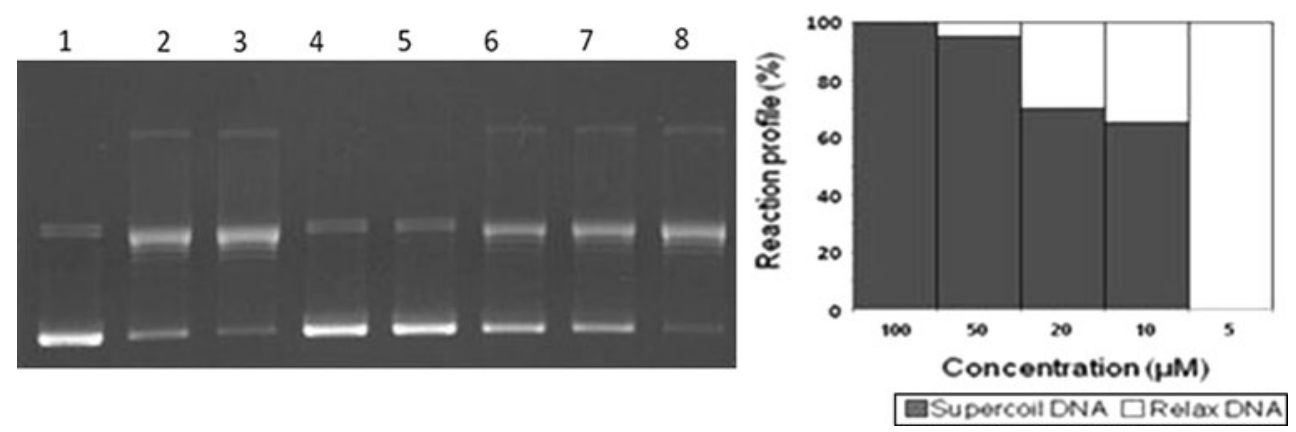

Fig. 1 The effect of Gossypol on supercoil relaxation activity of mammalian DNA topoisomerase I. A representative agarose gel photograph of supercoil relaxation in the presence of varying concentrations of Gossypol; lane 1, pBR322; lane 2, pBR322 with $1 \mathrm{u}$ of DNA topoisomerase I; lane 3, same as lane 2 in the presence
$10 \%$ DMSO; lanes 4-8, relaxations in the presence of 0.1 volume of $1,0.5,0.2,0.1$, and $0.05 \mathrm{mM}$ Gossypol, respectively (Fig. 1). Densitometric quantification of the reaction profile is shown next to gel photograph 
Fig. 2 A representative decatenation assay and its quantitative evaluation of topoisomerase IV-catalyzed reaction in the presence of Gossypol. Agarose gel photograph of decatenation activity of topo IV in the presence of 0.1 volume of $1 \mathrm{mM}$ (lane 3), $0.1 \mathrm{mM}$ (lane 4), and $0.02 \mathrm{mM}$ (lane 5) Gossypol. Lanes 1 and 2 correspond to negative and positive controls in the absence quantification of the reaction profile is shown on the right panel of Gossypol. Densitometric
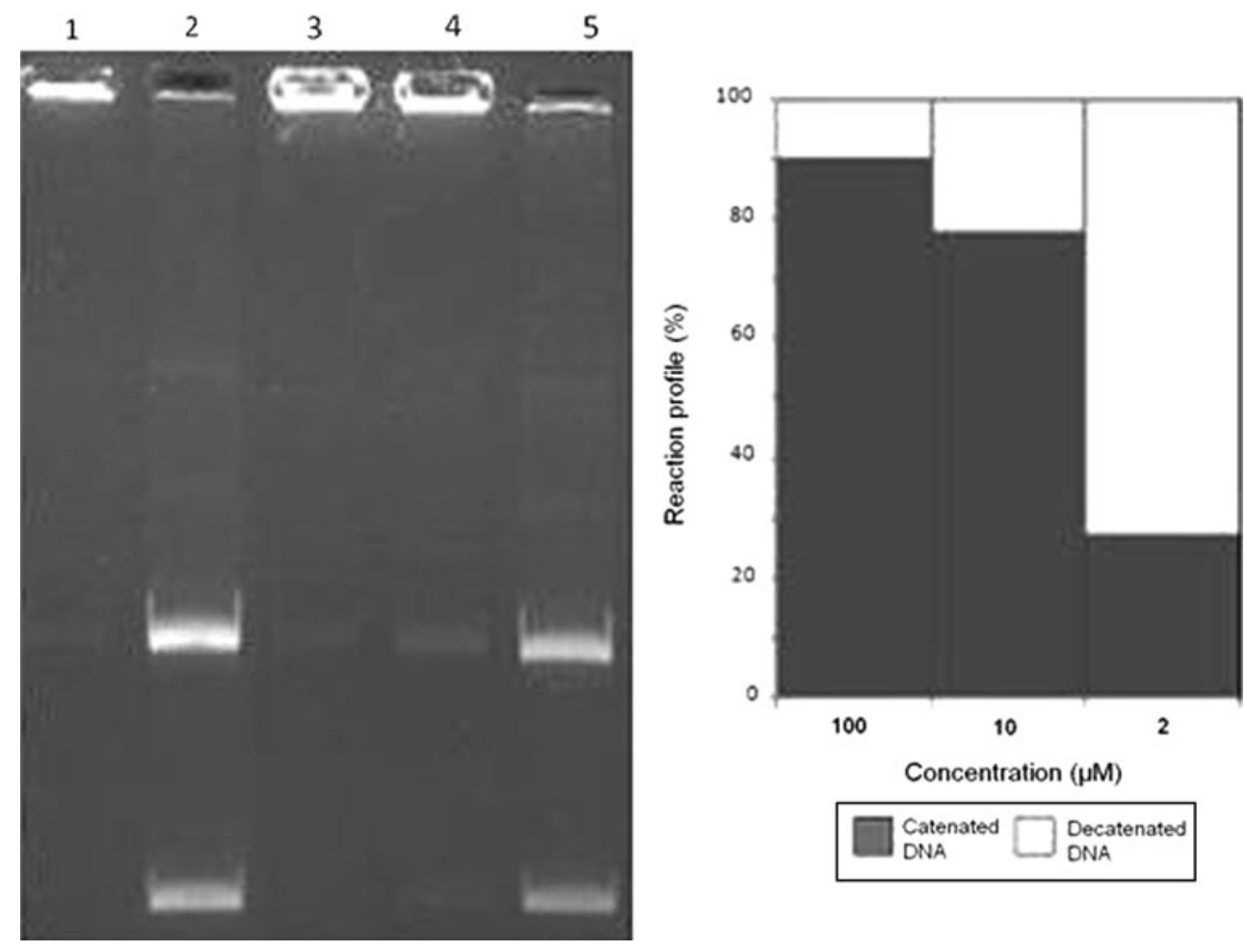

Fig. 3 Representative DNA strand break and covalent complex analyses of topoisomerase II-catalyzed reactions in the absence or the presence of Gossypol. a DNA strand break analyses.

b Covalent complex analyses. lane 1, linear DNA standard; lane 2, sc DNA substrate; lane 3, DNA substrate with topoisomerase II; lane 4, same as lane 2 in the presence $100 \%$ DMSO; lanes 5, 6, same as lane 2 in the presence of $2.5 \mathrm{mM}$ Etoposide (lane 5) and $10 \mathrm{mM}$ Gossypol (lane 6). Proteinase $\mathrm{K}$ digestion was omitted in lower panel of B (see text for detailed explanation)
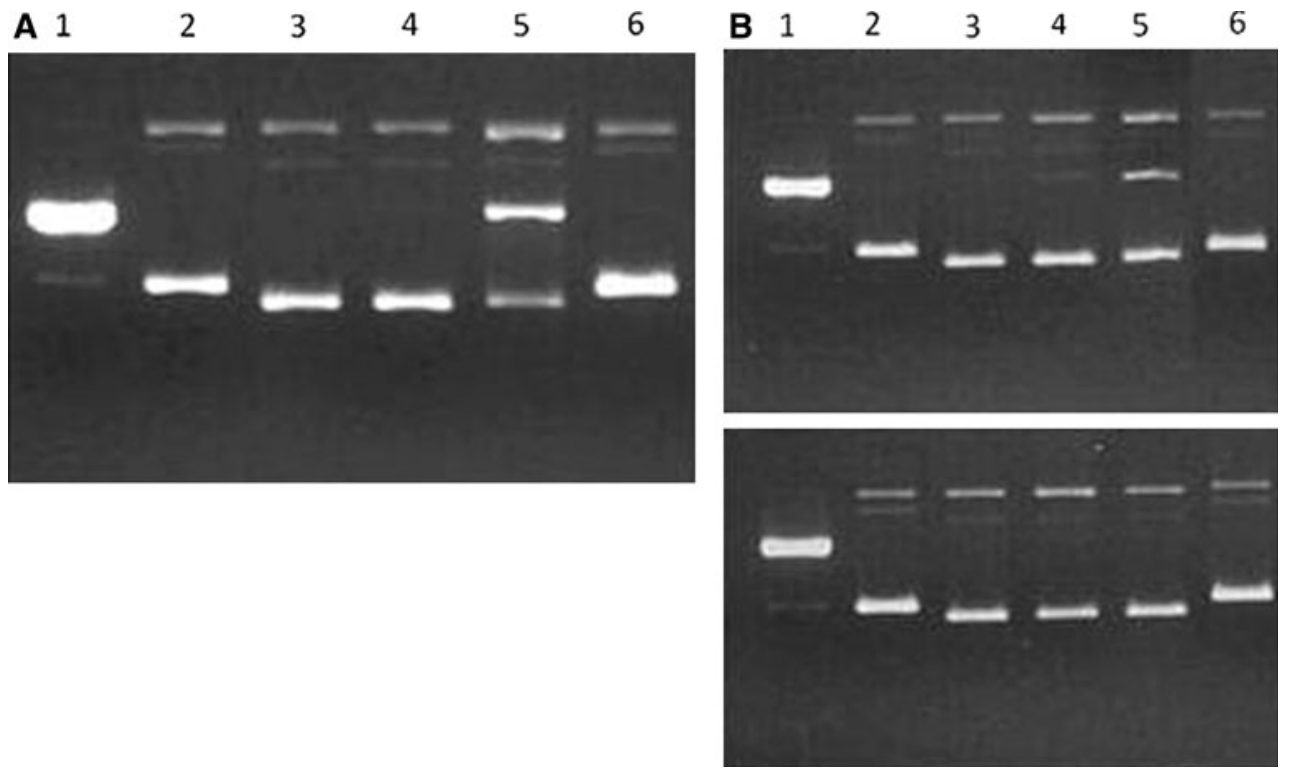

migration pattern with linear pRYG (Fig. 3a, lane 1). However, no strand breaks was identified in the presence of $2.5 \mathrm{mM}$ GSP (Fig. 3a, lane 6) as the reaction yielded a banding pattern similar to negative control that did not include the enzyme (Fig. 3a, lane 2). Increasing the concentration of GSP did not change the effect and the results were confirmed by monitoring the reactions using non Etd$\mathrm{Br}$ agarose gels as well as topoisomerase I reactions (data not shown).
We extended strand breaks experiments to cover the covalent complex analyses in the absence or the presence of Prot-K. The rationale in analyzing covalent complexes relies on the differential partition of protein-bound and proteinunbound DNA during PCI extraction by including or excluding Prot-K digestion following the termination of reactions. We used pBR322 in the same order of reactions as Fig. 3a during covalent complex analyses (Fig. 3b). Inclusion of 0.1 volume of $2.5 \mathrm{mM}$ Etoposide in topoisomerase II 
reaction resulted in double strand breaks as monitored with linearized pBR322 (Fig. 3b, upper lane 5) while the linear band disappeared if Prot-K digestion was omitted (Fig. 3b, lower panel, lane 5) indicating that protein-bound DNA was lost in PCI phase. The effect of DMSO (Fig. 3b, both panels, lane 4) was independent of Prot-K digestion and comparable to the positive control lane (Fig. 3b, both panels, lane 3). Gossypol did not result in the formation of strand breaks (Fig. 3b, both panels, lane 6). Like banding pattern of 3A, the reaction in the presence of $10 \mathrm{mM}$ GSP was similar to the negative control set in the absence of enzyme (Fig. 3b, both panels, lane 2). Incubation of plasmid DNA with either test compound or DMSO alone in the absence of enzyme was not influential on substrate DNA (data not shown); therefore, the results we obtained were based on the formation of enzymeDNA complex.

\section{Concluding Remarks}

Different classes of topoisomerase-targeting drugs target different sites in the formation of the enzyme-DNA complex. Given the structural diversity of topoisomerase-targeting drugs, a unified mechanism of action on enzyme-DNA complex by different compounds can hardly be proposed. Our results summarized above strongly suggest that GSP is both type I and type II topoisomerase-targeting agent. Separate incubation of GSP with enzymes did not alter its activity (data not shown) and reaction profiles showed gradual change in topoisomerase reaction products in response to the GSP concentration, which indicated that the effects we obtained were attributed to GSP on enzyme-DNA complex. Although exact characterization of the interaction of GSP with topoisomerase-DNA complex requires additional parameters to be measured, our results exclude the possibility of GSP acting as topoisomerase poison as no strand breakage was observed even at relatively high concentrations of GSP. Besides its chemical composition, our results also exclude the possibility of GSP acting as groove binding compound. Given the clinical importance of the catalytic inhibitors of DNA topoisomerases, GSP is a promising small molecule of natural source with a potential to be used in anticancer drug development.

Acknowledgments This study was supported by The Scientific and Technological Research Council of Turkey (TUBITAK) (Grant no. TBAG108T548 to ZT).

\section{References}

1. Wang, Y. C., \& Rao, P. N. (1984). Effect of gossypol on DNA synthesis and cell cycle progression of mammalian cells in vitro. Cancer Research, 44, 35-38.

2. Moon, D. O., Choi, Y. H., Moon, S. K., Kim, W. J., \& Kim, G. Y. (2011). Gossypol decreases tumor necrosis factor- $\alpha$-induced intercellular adhesion molecule-1 expression via suppression of NF- $\kappa \mathrm{B}$ activity. Food and Chemical Toxicology, 49, 999-1005.

3. Huang, Y. W., Wang, L. S., Chang, H. L., Ye, W., Sugimoto, Y., Dowd, M. K., et al. (2006). Effects of serum on (-)-gossypolsuppressed growth in human prostate cancer cells. Anticancer Research, 26, 3613-3620.

4. Volate, S. R., Kawasaki, B. T., Hurt, E. M., Milner, J. A., Kim, Y. S., White, J., et al. (2010). Gossypol induces apoptosis by activating p53 in prostate cancer cells and prostate tumor-initiating cells. Molecular Cancer Therapeutics, 9, 461-470.

5. Olgiati, K. L., \& Toscano, W. A., Jr. (1983). Kinetics of gossypol inhibition of bovine lactate dehydrogenase X. Biochemical and Biophysical Research Communications, 115, 180-185.

6. Baumgrass, R., Weiwad, M., Erdmann, F., Liu, J. O., Wunderlich, D., Grabley, S., et al. (2001). Reversible inhibition of calcineurin by the polyphenolic aldehyde gossypol. Journal of Biological Chemistry, 276, 47914-47921.

7. Adlakha, R. C., Ashorn, C. L., Chan, D., \& Zwelling, L. A. (1989). Modulation of $4^{\prime}$-(9-acridinylamino) metanesulfon-manisidide-induced, topoisomerase II-mediated DNA cleavage by gossypol. Cancer Research, 49, 2052-2058.

8. Wang, J. C. (1996). DNA topoisomerases. Annual Review Biochemistry, 65, 635-692.

9. Topcu, Z. (2001). DNA topoisomerases as targets for anticancer drugs. Journal of Clinical Pharmacy and Therapeutics, 26, 405-416.

10. Wang, J. C. (2002). Cellular roles of DNA topoisomerases: a molecular perspective. Nature Reviews, 3, 430-440.

11. D’Arpa, P., \& Liu, L. F. (1989). Topoisomerase-targeting antitumor drugs. Biochimica et Biophysica Acta, 989, 163-177.

12. Hsiang, Y. H., \& Liu, L. F. (1988). Identification of mammalian topoisomerase I as an intracellular target of the anticancer drug camptothecin. Cancer Research, 26, 1722-1726.

13. Sordet, O., Khan, Q. A., \& Pommier, Y. (2004). Apoptotic topoisomerase I-DNA complexes induced by oxygen radicals and mitochondrial dysfunction. Cell Cycle, 3, 1095-1097.

14. Galvez, M., Martín-Cordero, C., \& Ayuso, M. J. (2005). Iridoids as DNA topoisomerase I poisons. Journal of Enzyme Inhibition and Medicinal Chemistry, 20, 389-392.

15. Ishar, M. P., Singh, G., Singh, S., Sreenivasan, K. K., \& Singh, G. (2006). Design, synthesis, and evaluation of novel 6-chloro-/fluorochromone derivatives as potential topoisomerase inhibitor anticancer agents. Bioorganic \& Medicinal Chemistry Letters, 16, 1366-1370.

16. Kucukoglu, O., Ozturk, B., Kamataki, T., \& Topcu, Z. (2006). Inhibitory activities of Helichrysum taxa on mammalian type I DNA topoisomerase. Pharmaceutical Biology, 44, 189-193.

17. Alpan, S., Gunes, S., \& Topcu, Z. (2007). 1H-Benzimidazole derivatives as mammalian DNA topoisomerase I inhibitors. Acta Biochimica Polonica, 54, 561-565.

18. Canturk, P., Kucukoglu, K., Topcu, Z., Gul, M., \& Gul, H. I. (2008). Effect of some bis-Mannich bases and corresponding piperidinols on DNA topoisomerase I. Arzneimittel Forschung, $58,686-691$.

19. Topcu, Z., Ozturk, B., Kucukoglu, O., \& Kilinc, E. (2008). Flavonoids in Helichrysum pamphylicum inhibit mammalian type I DNA topoisomerase. Zeitschrift für Naturforschung C, 63, 69-74.

20. Coban, G., Zencir, S., Zupkó, I., Réthy, B., Gunes, H. S., \& Topcu, Z. (2009). Synthesis and biological activity evaluation of $1 \mathrm{H}$-benzimidazoles via mammalian DNA topoisomerase I and cytostaticity assays. European Journal of Medicinal Chemistry, 44, 2280-2285.

21. Sarikaya, D., Bilgen, C., Kamataki, T., \& Topcu, Z. (2006). Comparative cytochrome $\mathrm{P} 450-1 \mathrm{~A} 1,-2 \mathrm{~A} 6,-2 \mathrm{~B} 6,-2 \mathrm{C},-2 \mathrm{D} 6$, $-2 \mathrm{E} 1,-3 \mathrm{~A} 5$ and $-4 \mathrm{~B} 1$ expressions in human larynx tissue 
analysed at mRNA level. Biopharmaceutics \& Drug Disposition, 27, 353-359.

22. Mete, E., Gul, H. I., Canturk, P., \& Topcu, Z. (2010). Biological activity of 1-aryl-3-phenethylamino-1-propanone hydrochlorides and 3-aroyl-4-aryl-1-phenethyl-4-piperidinols on PC-3 cells and
DNA topoisomerase I enzyme. Zeitschrift für Naturforschung $C$, 65, 647-652.

23. Marini, J. C., Miller, K. G., \& Englund, P. T. (1980). Decatenation of kinetoplast DNA by topoisomerases. Journal of Biological Chemistry, 255, 4976-4979. 